NOTE

\title{
Critical swimming speed in groups of Atlantic salmon Salmo salar
}

\author{
Mette Remen ${ }^{1,4}$, Frida Solstorm ${ }^{1}$, Samantha Bui ${ }^{2}$, Pascal Klebert ${ }^{3}$, Tone Vågseth ${ }^{1}$, \\ David Solstorm ${ }^{1}$, Malthe Hvas ${ }^{1, *}$, Frode Oppedal ${ }^{1}$ \\ ${ }^{1}$ Institute of Marine Research, 5984 Matredal, Norway \\ ${ }^{2}$ Sustainable Aquaculture Laboratory - Temperate and Tropical, School of BioSciences, University of Melbourne, \\ Parkville 3010, Australia \\ ${ }^{3}$ SINTEF Fisheries and Aquaculture, 7465 Trondheim, Norway \\ ${ }^{4}$ Present address: Akvaplan-niva AS, Pirsenteret, Havnegata 9, 7462 Trondheim, Norway
}

\begin{abstract}
Critical swimming speed ( $U_{\text {crit }}$ ) has traditionally been measured in relatively small swimming tunnels with 1 fish alone. However, both increased flume lengths and swimming in groups are known to improve performance. Atlantic salmon Salmo salar farming is currently expanding to more exposed locations, which necessitates guidelines for limits in water current peak velocity to secure animal welfare. A large swim tunnel system was therefore developed which allowed for swimming trials at relevant stocking densities of Atlantic salmon comparable to the conditions in exposed sea cages. $U_{\text {crit }}$ was measured in groups of 3 size classes (small post-smolts, large post-smolts, adults) in this new swim tunnel and compared to measurements from individual fish in a smaller swim tunnel. $U_{\text {crit }}\left(\right.$ in $\mathrm{cm} \mathrm{s}^{-1}$ ) increased with size and was significantly lower in the smaller setup. Our results suggest that $U_{\text {crit }}$ can be used as a maximum current velocity tolerance threshold in exposed aquaculture, where longer periods above this value would be detrimental to the welfare and physiological function of the fish. This study represents a starting point in obtaining suitable current velocity profiles for farmed Atlantic salmon during the on-growing phase in sea cages.
\end{abstract}

KEY WORDS: Exposed aquaculture $\cdot$ Swim tunnel $\cdot U_{\text {crit }} \cdot$ Atlantic salmon $\cdot$ Flume length $\cdot$ School

\section{INTRODUCTION}

Since the pioneering work of Brett (1964), critical swimming speed $\left(U_{\text {crit }}\right)$ obtained from incremental velocity test protocols has been used as an important physiological parameter in countless studies to assess maximum aerobic performance in fish (Brett 1967, Hammer 1995, Farrell 2007). $U_{\text {crit }}$ is normally measured using swimming respirometers containing individual animals. However, in a natural setting many species of fish form groups, which may significantly reduce the cost of transport; for example, the time to exhaustion increased 10-fold when swimming 6 menhaden Brevoortia tyrannus together compared to

\footnotetext{
*Corresponding author: malthe.hvas@imr.no
}

swimming them alone (Hartwell \& Otto 1978), while a reduction in tail-beat frequency of fish in trailing school positions has been observed in several studies (Fields 1990, Herskin \& Steffensen 1998, Svendsen et al. 2003). Thus, the $U_{\text {crit }}$ traditionally obtained from individual fish might not be a representative indicator for swimming capabilities in species forming schools or groups. Furthermore, the use of relatively small swim tunnels has been subject to criticism because the restricted space reduces or eliminates the ability to change from a steady aerobic swimming gait to an unsteady and partly anaerobic burst and glide gait (Peake \& Farrell 2006, Tudorache et al. 2010). Increasing the flume length in a swim tunnel

() The authors 2016. Open Access under Creative Commons by Attribution Licence. Use, distribution and reproduction are unrestricted. Authors and original publication must be credited. 
resulted in higher $U_{\text {crit }}$ for carp Cyprinus carpio and charr Salvelinus fontinalis (Tudorache et al. 2007, 2010). When obtaining $U_{\text {crit }}$ values, the protocols and conditions often do not represent environments experienced by fish naturally, and thus the ecological relevance of $U_{\text {crit }}$ has been questioned; however, it is still the best available physiological measurement to estimate swimming performance and predict ecological consequences of fish that experience strong currents, such as migrating and pelagic species (Plaut 2001).

The Norwegian aquaculture industry of Atlantic salmon Salmo salar is currently expanding to more exposed farming sites (Bjelland et al. 2015), which are associated with higher water current velocities (Johansson et al. 2014). It is therefore important to know the limit for peak velocities to provide acceptable welfare for farmed $S$. salar. $U_{\text {crit }}$ has been reported in $S$. salar on several occasions previously (e.g. McKenzie et al. 1998, Wilson et al. 2007), but no studies have aimed at defining the upper velocity threshold in the on-growing phase in sea cages at relevant stocking densities.

To achieve such data, a much larger swim tunnel was built to better approximate sea cage conditions in a controlled experimental setting, where the assessment of swimming performance in groups of $S$. salar and enough space for the transition between swimming gaits was possible. $U_{\text {crit }}$ should therefore not be underestimated, and can then be used as an indicator for when peak current velocities in exposed sea cages become detrimental to fish welfare. Here we present the first data obtained from this new swim tunnel, where $U_{\text {crit }}$ was measured at 3 size classes (small post-smolts, large post-smolts, adults) at stocking densities relevant in aquaculture $(\sim 20 \mathrm{~kg}$ $\mathrm{m}^{-3}$ ). Furthermore, to test whether $U_{\text {crit }}$ actually is improved, and thus to validate the applicability of swimming groups in a larger swim tunnel, a comparison in experimental setup was made by also swimming post-smolts of 1 size class (large post-smolts) individually in a smaller traditional swim tunnel.

The aim of this study was therefore to produce relevant welfare guidelines concerning acceptable current velocities in growing $S$. salar in exposed sea cages by utilizing a new large swim tunnel design.

\section{MATERIALS AND METHODS}

\section{Animals}

Salmo salar were reared at the Matre Research Station in Norway. After smoltification, water was changed to full salinity and fish were kept in $5.3 \mathrm{~m}^{3}$ tanks at $14^{\circ} \mathrm{C}$ under continuous light conditions where they were fed size-appropriate commercial feed in excess. All experiments were conducted in accordance with Norwegian regulations on animal experimentation under permit number 6385.

\section{Swim tunnels}

The large swim tunnel (Fig. 1) was built using black polypropylene pipes, with an internal diameter of $36 \mathrm{~cm}$, forming an oval with 2 parallel sides. The water current was generated by a motor-driven pro-

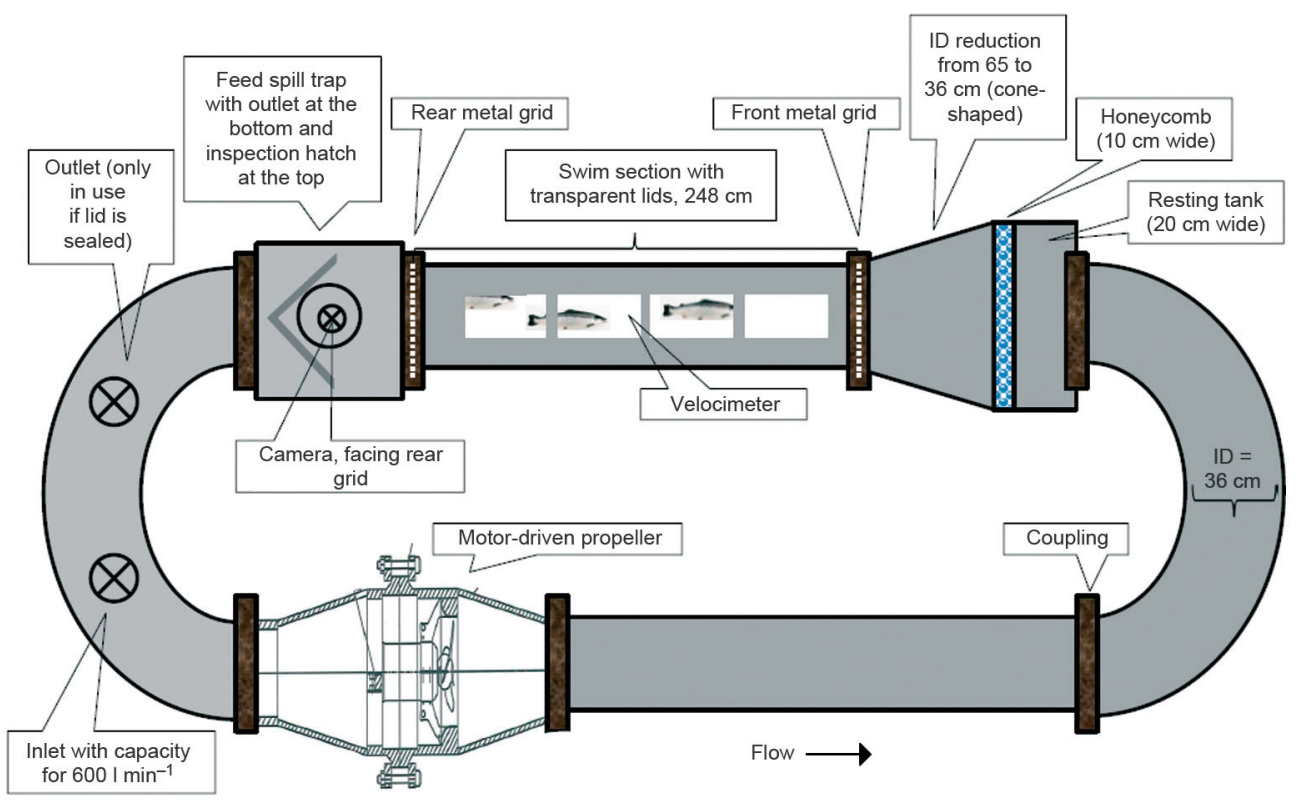

Fig. 1. Conceptual drawing of the large swim tunnel. ID: inner diameter 
peller (Flygt $4630,11^{\circ}$ propeller blade, Xylem Water Solutions), mounted inside a section with a larger diameter $(55 \mathrm{~cm})$ than the rest of the tunnel. The propeller speed in rounds per minute was controlled with a frequency converter (ITT Monitoring and Control). After passing the propeller, the water passed through approximately $5 \mathrm{~m}$ of pipe, including a resting tank, a honeycomb to straighten the flow (cell diameter $5 \mathrm{~mm}$ ), and a reduction cone (diameter reduced from 65 to $36 \mathrm{~cm}$ ) before entering the swim chamber section. The swim chamber section was $248 \mathrm{~cm}$ long with a volume of $252 \mathrm{l}$. The top opening towards the rear of the chamber could be partially removed to take out exhausted fish. A $15 \mathrm{~cm}$ high frame was built on top of the swim section to elevate the water level above the height of the pipe at the propeller section, and thus avoid air from being whisked into the water at the propeller. The top of the frame was covered with white semi-opaque plastic to avoid human disturbance during the acclimation period whilst still allowing light to pass through.

The water inlet was placed between the swim chamber section and the propeller, providing the system with $14^{\circ} \mathrm{C}$ fully aerated seawater at a flow rate of $421 \mathrm{~min}^{-1}$, using a pump submerged in an adjacent tank (Universal pump 1250, EHEIM). An acoustic Doppler velocimeter (Vectrino Lab Velocimeter, Nortek) was mounted in the middle of the swim section to measure the relationship between propeller speed and the water current velocity before the start. A maximum water current velocity of $140 \mathrm{~cm} \mathrm{~s}^{-1}$ was achieved, and this was enough for all fish to reach fatigue in the velocity increment tests.

Prior to swim tunnel challenges, tests were performed to investigate the velocity profile in the different sections of the tunnel with and without stocked fish. Measurements were taken at low $\left(17 \mathrm{~cm} \mathrm{~s}^{-1}\right)$, intermediate $\left(60 \mathrm{~cm} \mathrm{~s}^{-1}\right)$ and high current velocities $\left(100 \mathrm{~cm} \mathrm{~s}^{-1}\right)$ in the front, in the middle and in the rear end of the tunnel; all measurements were performed in a central transect along the chamber and at 5 different cross-sectional positions in the middle of the tunnel; in the centre and at $9 \mathrm{~cm}$ from the centre towards the top, bottom, right and left. No differences were found in velocity measured in the front, middle and rear end of the swimming section. In the cross-sectional analysis, higher velocities were observed in the lower section compared to the centre, being on average 1.7, 4.3 and $7.7 \mathrm{~cm} \mathrm{~s}^{-1}$ higher at low, intermediate and high velocity, respectively (10, 7 and $8 \%$ difference). No differences in velocity were found between the centre, and the upper, right and left sections of the tunnel. Centre measurements are presented throughout the manuscript. This implies that $U_{\text {crit }}$ may at maximum be $8 \%$ higher than what is reported in the present paper. However, as fish were not observed to prefer this section of the swim tunnel, the possible underestimation of $U_{\text {crit }}$ was considered to be within acceptable limits. Adding 18 post-smolts (5.4 kg biomass) did not change the centre velocity of the system.

Since the cross-sectional area of the fish did not exceed $10 \%$ of the water tunnel cross-section at higher velocities in any of the trials, solid blocking was not corrected for (Bell \& Terhune 1970, Plaut 2001). However, at low velocities, fish did occasionally overlap in the horizontal plane, thereby exceeding $10 \%$ of the water tunnel cross-section.

The swimming section of the small flume was $47 \mathrm{~cm}$ long, $15 \mathrm{~cm}$ wide and $14.5 \mathrm{~cm}$ deep and has previously been described by Steinhausen et al. (2005). In this setup, water current velocity was corrected for solid blocking effects according to Bell \& Terhune (1970).

\section{$U_{\text {crit }}$ protocols}

In the large tunnel, the following swim trials were made: Groups of 3, 3 and 4 adults, groups of 16, 17 and 16 large post-smolts, and 4 groups of 28 small post-smolts. In the small swim tunnel, 10 large postsmolts were tested individually. The weight, condition factor of the fish and the stocking density in the swim tunnel trials are summarized in Table 1.

Fish were transferred from the holding tank to their swim tunnel during the afternoon on the day before measurements after being fed their daily ration. All fish in the holding tank were lightly sedated (Finquel, $20 \mathrm{mg} \mathrm{l}^{-1}$ ) in order to minimize sampling stress and achieve random selection. Prior to transfer into the swimming chamber, fork length, body width and height were measured. After consciousness was regained, velocity was set to $\sim 0.5$ body lengths per sec-

Table 1. Weight, condition factor, stocking density in the swim tunnel and the total number of Atlantic salmon tested in each group $(\mathrm{N})$. Data are mean \pm SEM

\begin{tabular}{|lcccc|}
\hline & $\begin{array}{c}\text { Weight } \\
(\mathrm{g})\end{array}$ & $\begin{array}{c}\text { Condition } \\
\text { factor }\end{array}$ & $\begin{array}{c}\text { Density } \\
\left(\mathrm{kg} \mathrm{m}^{-3}\right)\end{array}$ & $\mathrm{N}$ \\
\hline Small post-smolts & $80 \pm 1$ & $1.07 \pm 0.02$ & $8.8 \pm 0.1$ & 112 \\
Large post-smolts & $289 \pm 9$ & $1.19 \pm 0.01$ & $16.3 \pm 0.3$ & 49 \\
$\begin{array}{l}\text { Adults } \\
\text { Large post-smolts } \\
\text { (small flume) }\end{array}$ & $300 \pm 12$ & $1.20 \pm 0.03$ & $29 \pm 4$ & 10 \\
\hline
\end{tabular}


ond $\left(\mathrm{BL} \mathrm{s}{ }^{-1}\right)$, and fish were left to acclimate overnight. The effect of anaesthesia on swimming performance is negligible after an overnight recovery period (Hayashida et al. 2013).

During $U_{\text {crit }}$ measurements, water current velocity was increased by $\sim 0.5 \mathrm{BL} \mathrm{s}^{-1}$ every $20 \mathrm{~min}$ until fish were fatigued, which was defined as lying on the side against the rear grid for $15 \mathrm{~s}$. Fish were monitored using cameras and fatigued fish were rapidly taken out by hand and killed with a blow to the head. Following the trial, fish were weighed and sexed, and the gonads in maturing fish were taken out and weighed. Oxygen saturation was $>94 \%$ of air saturation, and temperature remained constant in both swim tunnels throughout the experiments. Critical swimming speed was calculated according to Brett (1964) as:

$$
U_{\text {crit }}=U_{\mathrm{f}}+\frac{t_{\mathrm{f}} U_{\mathrm{i}}}{t_{\mathrm{i}}}
$$

where $U_{\mathrm{f}}$ is the water velocity of the last completed velocity increment, $t_{\mathrm{f}}$ is the time spent at the last velocity increment, $t_{\mathrm{i}}$ is the time spent at each velocity and $U_{\mathrm{i}}$ is the magnitude of the velocity increment.

\section{Statistical analysis}

Analyses were performed in Sigmaplot 12.3. Since both size and $U_{\text {crit }}$ were similar in the separate swim trials within each size class, $U_{\text {crit }}$ values from the large tunnel were pooled for each size class. It was evident that some of the large post-smolts and adults were sexually maturing, and due to the possible effect of maturation on $U_{\text {crit }}$ (Williams \& Brett 1987), these individuals were removed from the statistical analyses. Because data did not have equal variance even when a log transformation was made, an ANOVA on ranks with Dunn's post hoc test was used to test for differences in $U_{\text {crit }}$ between size class and experimental setup. A p-value $<0.05$ was considered significant. All data are presented as mean \pm SEM.

\section{RESULTS}

In the large swim tunnel, $U_{\text {crit }}$ increased with size class from (mean $\pm \mathrm{SE}$ ) $80.6 \pm 0.5$ to $90.9 \pm 1.2$ and $99.5 \pm 3.7 \mathrm{~cm} \mathrm{~s}^{-1}$ in small post-smolts $(80 \pm 1 \mathrm{~g}, \mathrm{n}=$ 112), large post-smolts $(289 \pm 9 \mathrm{~g}, \mathrm{n}=41)$ and adults $(1750 \pm 175$ g, $\mathrm{n}=8)$, respectively (Fig. 2). However, only small post-smolts were statistically different from the other size classes in the large swim tunnel.

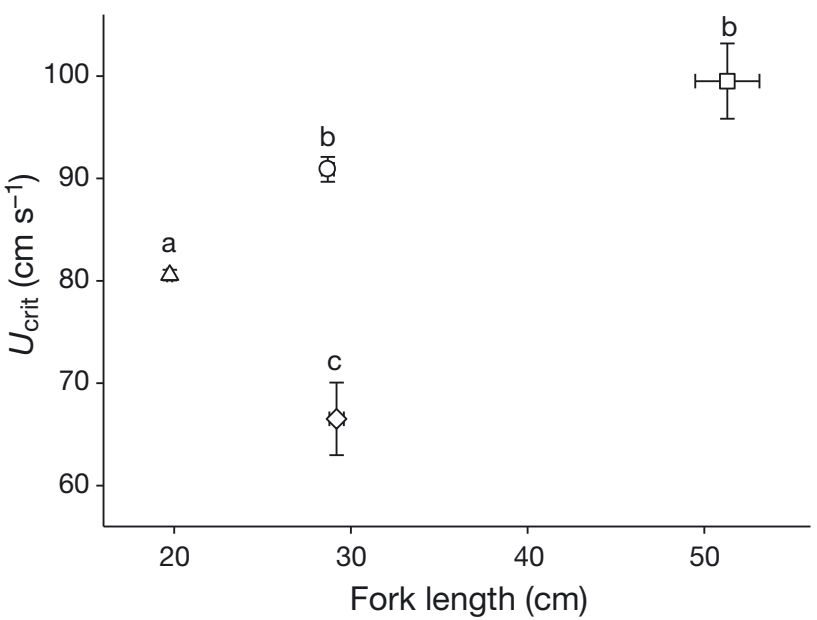

Fig. 2. Critical swimming speed ( $\left.U_{\text {crit }}\right)$ and fork length measured in groups of Atlantic salmon using the large tunnel in small post-smolts (triangle), large post-smolts (circle), adults (square), and large post-smolts tested individually in the small tunnel (diamond). Different letters indicate a statistical difference in $U_{\text {crit }}$. Data are mean \pm SEM

The relative $U_{\text {crit }}$ (expressed as $\mathrm{BL} \mathrm{s} \mathrm{s}^{-1}$ ) decreased with size class (not illustrated), but since the purpose of this study was to find threshold velocity values for exposed salmon farming, absolute $U_{\text {crit }}$ values are more informative. $U_{\text {crit }}$ from larger post-smolts (300 \pm $12 \mathrm{~g}, \mathrm{n}=10$ ) tested individually in the small swimming tunnel was only $66.5 \pm 3.5 \mathrm{~cm} \mathrm{~s}^{-1}$, which was significantly lower compared to all 3 size classes in the other setup (Fig. 2).

In the small tunnel, fish generally preferred to hold station against the current by using their pectoral fins as depressors at the lower velocities, and switched between swimming and holding station as velocity increased. The fish were also observed to rest their tail on the rear grid, predominantly at the higher velocities. In the large tunnel, fish were not observed to use their pectoral fins as depressors. At low velocity, most of the fish preferred the rear section of the tunnel, and held their position in the group with steady swimming. As the current velocity increased, fish generally spread out, and burst and glide movements were observed. Just prior to fatigue, fish would fall back on the grid a few times before they were no longer able to remove themselves from the grid.

\section{DISCUSSION}

Several previous studies have shown that swimming in a group decreases the cost of transport (Hartwell \& Otto 1978, Fields 1990, Herskin \& Steffensen 1998, Svendsen et al. 2003), and a longer flume length 
increases $U_{\text {crit }}$ by allowing transition between swimming gaits (Peake \& Farrell 2006, Tudorache et al. $2007,2010)$. Therefore, it is not surprising that $U_{\text {crit }}$ was significantly lower when post-smolts were tested individually in a smaller swim tunnel.

In Cyprinus carpio, flume lengths above 6.6 BL did not improve $U_{\text {crit, }}$ which suggests that flumes should be close to this length to enable a proper transition from steady to unsteady swimming (Tudorache et al. 2007). In accordance with this, in the present study anaerobically fuelled burst and glide swimming in post-smolts was only observed in the larger tunnel with a flume length of 8.6 BL, while unsteady swimming appeared to be inhibited in the small tunnel with a flume length of $1.6 \mathrm{BL}$. However, the flume length in the large tunnel only corresponded to 4.8 BL in adult Salmo salar. It is therefore possible that we underestimated $U_{\text {crit }}$ in adults if unsteady swimming was inhibited.

The relative contribution of flume length and swimming in groups cannot be estimated directly with the experimental design used here. In Salvelinus fontinalis, $U_{\text {crit }}$ improved by $12 \%$ when flume length was increased from 2.9 to 6.2 BL (Tudorache et al. 2010), and in our study, a longer flume improved $U_{\text {crit }}$ by $37 \%$ in large post-smolts. This relatively greater improvement compared to Tudorache et al. (2010) indicates that both flume length and swimming in groups played a significant role in increasing $U_{\text {crit }}$ for $S$. salar post-smolts. However, in the shortnose sturgeon Acipenser brevirostrum, there was no difference in $U_{\text {crit }}$ between testing fish individually and in groups, while $U_{\text {crit }}$ was $22 \%$ higher when using a longer flume (Deslauriers \& Kieffer 2011). To our knowledge, sturgeons do not normally swim in schools; thus, the ability to take advantage of group swimming is likely to be highly species-dependent.

Since the $U_{\text {crit }}$ measurements presented here were obtained at relevant stocking densities $\left(\sim 20 \mathrm{~kg} \mathrm{~m}^{-3}\right)$ in a swim tunnel of sufficient length to allow transition between swimming gaits for post-smolts, we suggest that these values can be used by the salmon aquaculture industry as a maximum current velocity tolerance threshold when fast currents occur in periods that are of equal, or shorter duration than $20 \mathrm{~min}$ (the increment interval used in this study). Longer periods with current velocities higher than $U_{\text {crit }}$ cannot be considered acceptable with respect to welfare or physiological function, because exhaustion results in a loss of locomotor control, a depletion of muscle glycogen reserves, accumulation of lactate, release of catecholamines and sometimes death (Wood 1991, Burnett et al. 2014). Furthermore, after a period with current velocities approaching $U_{\text {crit, }}$ time is required to recover from the metabolic, acid-base and endocrine disturbances that follow exhaustive exercise which reduces the capacity for growth (Milligan 1996). $U_{\text {crit }}$ can therefore be termed the upper velocity tolerance limit, and it must be emphasized that considerably lower velocities are required for the principal part of the production to enable efficient feeding and growth. This was recently demonstrated in S. salar post-smolts where growth rates were significantly higher at water current velocities of 0.8 compared to 1.5 $\mathrm{BLs}^{-1}$ (Solstorm et al. 2015).

In conclusion, we have introduced a new swim tunnel system, much larger than what has been used previously, as a viable approach in obtaining ecologically relevant data on swimming performance in groups of fish. Swimming $S$. salar in this tunnel at relevant stocking densities produced a significantly higher $U_{\text {crit }}$ compared to single fish in a smaller swim tunnel. The $U_{\text {crit }}$ values reported here should be more similar to the conditions experienced in commercial sea cages, and can therefore be used as guidelines for the aquaculture industry for peak water current velocity thresholds. In future studies, it will also be important to investigate how factors such as temperature, feeding and stress affect swimming performance to provide more detailed guidelines for animal welfare in exposed salmon farming.

Acknowledgements. We thank the staff at Matre Research station for rearing the fish and for technical assistance; Linda Oldeide for performing trials in the small tunnel; Reidar Grindheim (Johansen Rør AS, Skånevik, Norway) for help with development and building of the large swim tunnel; and Vidar Foldnes (Xylem Water Solutions Norge AS, Nesttun, Norway) and Olav Arne Sletten (Masfjorden Elektro, Haugsvær, Norway) for the installation of the motor-driven propeller in the swim tunnel. The work was synergistically funded by several Norwegian Research Council projects (Exposed Farming) with participating industry partners (CREATE, Exposed Aquaculture Operations) and internal funds at the Institute of Marine Research from the Ministry of Trade, Industry and Fisheries.

\section{LITERATURE CITED}

Bell WH, Terhune LDB (1970) Water tunnel design for fisheries research. Tech Rep 195. Fisheries Research Board of Canada, Ottawa

Bjelland H, Føre M, Lader P, Kristiansen D and others (2015) Exposed aquaculture in Norway. Proceedings from OCEANS' 15 MTS/IEEE, Washington, USA, 19-22 October 2015. http://ieeexplore.ieee.org/xpl/articleDetails.jsp? arnumber $=7404486$

Brett JR (1964) The respiratory metabolism and swimming performance of young sockeye salmon. J Fish Res Board Can 21:1183-1226 
Brett JR (1967) Swimming performance of sockeye salmon (Oncorhynchus nerka) in relation to fatigue time and temperature. J Fish Res Board Can 24:1731-1741

*Burnett NJ, Hinch SG, Braun DC, Casselman MT, Middleton CT, Wilson SM, Cooke SJ (2014) Burst swimming in areas of high flow: delayed consequences of anaerobiosis in wild adult sockeye salmon. Physiol Biochem Zool 87: 587-598

Deslauriers D, Kieffer JK (2011) The influence of flume length and group size on swimming performance in shortnose sturgeon Acipenser brevirostrum. J Fish Biol 79:1146-1155

Farrell AP (2007) Cardiorespiratory performance during prolonged swimming tests with salmonids: a perspective on temperature effects and potential analytical pitfalls. Philos Trans R Soc Lond B Biol Sci 362:2017-2030

Fields PA (1990) Decreased swimming effort in groups of pacific mackerel (Scomber japonicus). Am Zool 30:A134

Hammer C (1995) Fatigue and exercise tests with fish. Comp Biochem Physiol A Mol Integr Physiol 112:1-20

Hartwell SI, Otto RG (1978) Swimming performance of juvenile menhaden (Brevoortia tyrannus). Trans Am Fish Soc 107:793-798

Hayashida K, Nii H, Tsuji T, Miyoshi K, Hamamoto S, Ueda $H$ (2013) Effects of anesthesia and surgery on $U_{\text {crit }}$ performance and $\mathrm{MO}_{2}$ in chum salmon, Oncorhynchus keta. Fish Physiol Biochem 39:907-915

Herskin J, Steffensen JF (1998) Energy savings in sea bass swimming in a school: measurements of tail beat frequency and oxygen consumption at different swimming speeds. J Fish Biol 53:366-376

* Johansson D, Laursen F, Fernö A, Fosseidengen JE and others (2014) The interaction between water currents and salmon swimming behaviour in sea cages. PLOS ONE 9: e97635

McKenzie DJ, Higgs DA, Dosanjh BS, Deacon G, Randall DJ (1998) Dietary fatty acid composition influences swimming performance in Atlantic salmon (Salmo salar) in seawater. Fish Physiol Biochem 19:111-122

Milligan CL (1996) Metabolic recovery from exhaustive

Editorial responsibility: Chris Noble,

Tromsø, Norway exercise in rainbow trout. Comp Biochem Physiol A Mol Integr Physiol 113:51-60

Peake S, Farrell A (2006) Fatigue is a behavioural response in respirometer-confined smallmouth bass. J Fish Biol 68: 1742-1755

Plaut I (2001) Critical swimming speed: its ecological relevance. Comp Biochem Physiol A Mol Integr Physiol 131: $41-50$

Solstorm F, Solstorm D, Oppedal F, Fernö A, Fraser TWK, Olsen RE (2015) Fast water currents reduce production performance of post-smolt Atlantic salmon Salmo salar. Aquacult Environ Interact 7:125-134

* Steinhausen MF, Steffensen JF, Andersen NG (2005) Tail beat frequency as a predictor of swimming speed and oxygen consumption of saithe (Pollachius virens) and whiting (Merlangius merlangus) during forced swimming. Mar Biol 148:197-204

Svendsen JC, Skov J, Bildsoe M, Steffensen JF (2003) Intraschool positional preference and reduced tail beat frequency in trailing positions in schooling roach under experimental conditions. J Fish Biol 62:834-846

* Tudorache C, Viaenen P, Blust R, De Boeck G (2007) Longer flumes increase critical swimming speeds by increasing burst-glide swimming duration in carp Cyprinus carpio, L. J Fish Biol 71:1630-1638

* Tudorache C, O'Keefe RA, Benfey TJ (2010) Flume length and post-exercise impingement affect anaerobic metabolism in brook charr Salvelinus fontinalis. J Fish Biol 76: 729-733

Williams IV, Brett JR (1987) Critical swimming speed of Fraser and Thompson River pink salmon (Oncorhynchus gorbuscha). Can J Fish Aquat Sci 44:348-356

Wilson CM, Friesen EN, Higgs DA, Farrell AP (2007) The effect of dietary lipid and protein source on the swimming performance, recovery ability and oxygen consumption of Atlantic salmon (Salmo salar). Aquaculture 273:687-699

Wood CM (1991) Acid-base and ion balance, metabolism, and their interactions, after exhaustive exercise in fish. J Exp Biol 160:285-308

Submitted: May 30, 2016; Accepted: November 8, 2016 Proofs received from author(s): December 1, 2016 